\title{
LAS MEDIDAS CAUTELARES EN EL ORDENAMIENTO JURIDICO CHILENO: SU TRATAMIENTO EN ALGUNAS LEYES ESPECIALES
}

\author{
Juan Carlos Marín González ${ }^{*}$
}

\section{Planteamiento}

La concepción de las medidas cautelares está cambiando en Chile. Esta concepción se construyó en base a la regulación contenida en el título $\mathrm{V}$, del libro II, del Código de Procedimiento Civil (CPC). Dos son las ideas matrices que destacan de esta construcción: (i) en primer lugar, las medidas cautelares sirven para asegurar el resultado práctico de la acción, pero en ningún caso pueden anticipar parte o el total de la pretensión del actor. (ii) En segundo término, las medidas cautelares son esencialmente patrimoniales, esto es, pretenden asegurar uno o más bienes en pos de una futura ejecución forzosa. Sobre estas dos ideas, repito, se ha elaborado todo el edificio dogmático de la tutela cautelar en el país ${ }^{1}$.

En los últimos años, sin embargo, diversos cuerpos normativos se han apartado de esta tradicional visión. Lo anterior no es un fenómeno peculiar de nuestro país, sino una tendencia casi uniforme en el derecho comparado. Esta situación encuentra en parte su justificación por lo largo e ineficaces que resultan los procedimientos judiciales, y por la esperanza - muchas veces infundada - de que la tutela cautelar va a dar una solución pronta y expedita del litigio. Es cierto que un buen sistema de medidas cautelares constituye un instrumento valioso del cual hoy en día los ordenamientos jurídicos no pueden prescindir ${ }^{2}$, pero de allí a creer que estamos frente a una fórmula mágica que va a finalizar los múltiples problemas que aquejan a los procedimientos judiciales, hay largo trecho que

\footnotetext{
*Doctor en Derecho. Profesor e investigador del Centro de Estudios de la Justicia, Facultad de Derecho, Universidad de Chile. Profesor de derecho procesal Universidad Adolfo Ibáñez.

1 Véase al respecto mi libro Las medidas cautelares en el proceso civil cbileno, Jurídica de Chile, 2004, págs. 307 y ss.

2 En España, incluso, el Tribunal Constitucional Español ha establecido una sólida jurisprudencia en orden a reconocer la necesaria vinculación que existe entre la tutela judicial efectiva (derecho fundamental ex artículo 24.1 CE) y la adopción de medidas cautelares. A este respecto en la sentencia 238/1992, de 17 de diciembre, el TCE señaló en el fundamento jurídico tercero: Ciertamente, el artículo 24.1 CE no hace referencia alguna a las medidas cautelares ni a la potestad de suspensión. Pero de ello no puede inferirse que quede libre el legislador de todo límite para disponer o no medidas de aquel género o para ordenarlas sin condicionamiento constitucional alguno. La tutela judicial ha de ser, por imperativo constitucional, «efectiva», y la medida en que lo sea o no ha de hallarse en la suficiencia de las potestades atribuidas por ley a los órganos del poder judicial para, efectivamente, salvaguardar los intereses o derechos cuya protección se demanda. Por ello, es preciso reiterar ahora lo que afirmamos en nuestra STC 14/1992 (RTC 1992 \14), fundamento jurídico $7 .^{\circ}$, esto es, que la tutela judicial no es tal sin medidas cautelares que aseguren el efectivo cumplimiento de la resolución definitiva que recaiga en el proceso. [STC (Pleno), RTC 1992\238. Cuestión de inconstitucionalidad promovida por la Sala de lo Contencioso-Administrativo de la Audiencia Territorial de Cáceres]. Sobre el hecho de si la tutela cautelar tiene fundamento constitucional o es simplemente fruto de la libertad normativa del legislador ordinario, vid. ORTELLS, «Doctrina jurisprudencial del Tribunal Constitucional sobre la tutela judicial cautelar en materias no penales (1981-1996)», en Tribunales de Justicia 6/1997, págs. 623-642.
} 
recorrer. Sin ir más lejos, las medidas cautelares presentan varios inconvenientes que —en manos de jueces poco preparados- pueden transformarse en herramientas sumamente abusivas ${ }^{3}$.

De este modo, en este trabajo, junto con explicar brevemente la evolución que la tutela cautelar ha experimentado en el derecho comparado, y los fines que sucesivamente ha comprendido, me concentraré en la reglamentación que algunas leyes especiales han efectuado en el último tiempo de ella.

\section{Breve evolución de la tutela cautelar.}

Constituye un lugar común que toda la construcción dogmática de las medidas cautelares se erige en torno a paliar el tiempo que emplean los tribunales de justicia en resolver el conflicto ante ellos planteado. Este tiempo, necesario para que las afirmaciones de las partes puedan ser probadas y, en definitiva, para lograr la convicción en el juez al momento de resolver el litigio, puede transformarse paradójicamente en el gran enemigo del proceso y, como se comprenderá, en el principal obstáculo que encuentra el sujeto activo de la relación procesal. Al respecto, no olvidemos que desde antiguo rige el principio de que durante la tramitación del procedimiento nada debe innovarse en él (lite pendente nibil innovetur). Esto último encuentra un razonable fundamento en la incertidumbre que todo proceso conlleva, indecisión que sólo se dilucida una vez que se dicta la sentencia definitiva y, más precisamente, una vez que ésta adquiere firmeza ${ }^{4}$.

Si bien lo anterior es en principio plausible, no puede hacernos olvidar que de una u otra forma favorece la posición del sujeto pasivo de la relación procesal, el cual puede esperar «tranquilamente» el desarrollo completo del iter procesal sabiendo que durante ese tiempo la cosa sobre la cual se litiga permanecerá en su poder, y que su patrimonio no sufrirá detrimento alguno ${ }^{5}$. CARNELUTTI a este respecto observaba que «cuando dos contienden acerca del disfrute de una cosa, se halla en posición indiscutiblemente superior el que la posee. Las razones de esta superioridad son prácticas e intuitivas: basta, para mencionar una de ellas, imaginar

3 De hecho las medidas cautelares han sido referidas como «bombas nucleares» al interior del procedimiento civil inglés. Donaldson, Master of Rool, Bank Mellat v. Nikpour (1986) F.S.R. págs. 87-92. A ello se añade, como indica ANDREWS, que dicha metáfora nos puede poner a todos nerviosos, especialmente desde el momento que los tribunales ingleses han sugerido que una solicitud de este tipo de órdenes, bien presentada, será muy difícil que sea denegada. «Si es esto correcto, lo que se sigue es que es el abogado, y no el juez, quien tiene en sus dedos el detonador nuclean». Principles of civil procedure, Londres, 1994, pág. 160.

4 Montero Aroca en este sentido afirma que «en principio la esfera jurídica sustancial de las personas que aparecen como partes en un proceso no debería verse afectada por la iniciación de éste. El proceso, en su propia existencia, responde a una situación de incertidumbre y ésta no debería permitir alteraciones en la situación jurídica de las partes. Estas alteraciones sólo deberían producirse cuando de la incertidumbre se pasa a la certeza, esto es, cuando el proceso ha llegado a establecer el reparto irrevocable de los derechos y las obligaciones». Trabajos de derecho procesal, Barcelona, 1988,pág. 424.

5 Sin perjuicio, claro está, de que puede además tomar acciones que hagan desaparecer sus bienes, transferirlos, deteriorarlos, y emplear cuanto recurso procesal tenga a su alcance a efectos de dilatar el proceso incoado en su contra. 
la hipótesis de dos aspirantes a una herencia importante, poseída por uno y reclamada por el otro: el poseedor tiene, por lo menos, sobre su adversario, y con mayor motivo si éste no cuenta con otros bienes de fortuna, la ventaja de sacar de la propia cosa controvertida los medios para sostener el proceso» ${ }^{6}$.

Frente a esta realidad, y a efectos de no hacer ilusorio el cumplimiento de la eventual sentencia que se dicte acogiendo la pretensión del demandante, los ordenamientos jurídicos de tradición continental han contemplado una serie de medidas que englobadas bajo diferentes nombres (cautelares, precautorias, conservativas, asegurativas, provisionales, entre otros) buscan precisamente asegurar la efectividad de dicho cumplimiento?

Ésta fue precisamente la filosofía que inspiró a los códigos procesales decimonónicos que contemplaron diversos mecanismos para resguardar los eventuales derechos del demandante y, de este modo, evitar futuros fraudes a la acción de la justicia, pero sin introducir ninguna innovación en la posesión de los bienes mientras se tramitaba el proceso. Esta filosofía se encuentra reflejada palmariamente en la Curia Filípca Mexicana, que al respecto señaló lo siguiente:

Si el actor precisamente ha de demandar en juicio lo que se le debe y en la manera, lugar y tiempo en que se le debe, sin que pueda entenderse por ningún capítulo en la cosa que demanda, tampoco puede pretender que se haga novedad alguna en la misma cosa demandada hasta que sea terminado el pleito por la sentencia definitiva, porque es un principio elemental de la práctica forense, que pendiente el pleito nada debe innovarse. Este principio forma en el código canónico de las decretales, una oración completa, y constituye un título verdadero; y tiene lugar tanto en la propiedad, como en la posesión, como en el uso y en cualquier otro derecho. De aquí es que la cosa que se ha hecho litigiosa a virtud de una demanda, debe conservarse en el mismo estado, sin diferencia alguna, que el que antes de la misma demanda, sin que el actor pueda pretender que se haga en ella la más leve novedad, sino que el reo debe gozarla con la propia libertad que la gozaba antes del litigio. Por la misma razón está establecido en nuestra práctica otro principio, que viene a ser como corolario o consecuencia precisa del anterior. Ningún juicio debe comenzar por secuestro o embargo de la cosa litigiosa. Y ambas reglas se fundan nada menos que en la fuerza del derecho natural, que no permite que la voluntad simple de un hombre,

6 Sistema de derecho procesal, traducción de Niceto Alcalá-Zamora y Santiago Sentís Melendo, t. I, Buenos Aires, 1944, págs. 249 y 250.

7 Así, Manresa y Reus, a propósito del embargo preventivo español regulado en la Ley de enjuiciamiento civil de 1855, señalaban que «en todos [los] tiempos han adoptado las leyes medidas provisionales en beneficio de los acreedores, para que en su día pudieren conseguir el reintegro de lo que se le adeudaba o la reivindicación de la cosa, en el caso de que llegaren a obtener una sentencia favorable». Ley de enjuiciamiento civil comentada y explicada, t. IV, Madrid, 1861, pág. 241. 
Marín - las medidas cautelares en el ordenamiento jurídico chileno...

sea bastante para causar a otro el mas leve perjuicio y trastorno en sus intereses o derechos. [...] Ya que queda sentado, que ningún juicio debe comenzar por embargo de la cosa demandada, mas esta regla tiene, como todas, algunas excepciones. Seis pone la ley de Partida $[\ldots]^{8}$.

Notable construcción que refleja nítidamente el ideal que regía en aquellos años y cuyo fundamento se hacía descansar nada menos que en el derecho natural. Pero, como se comprenderá, si se establecía que los bienes en disputa permanecían bajo el dominio del sujeto pasivo de la relación procesal, quien en principio no perdía ninguno de los atributos que la propiedad daba sobre ellos, era en el entendido de que dichos bienes no sufrirían deterioro alguno ni serían transferidos en fraude de los acreedores. También esto último se sustentaba en la fuerza del derecho natural: la confianza en la actuación de buena fe del deudor que no iba a realizar ninguna conducta que perjudicase los derechos o intereses de su acreedor. De allí que la regla de no intervención reconocía algunas excepciones que precisamente fueron recogidas en el CPC chileno bajo el título V del libro II denominado De las medidas precautorias.

Ahora bien, durante el siglo XX y principalmente a partir de su segunda mitad la originaria «tranquilidad» de que gozaba el demandado ha sido puesta en entredicho. El objeto sobre el cual se desenvolvían los litigios se ve alterado; surgen nuevos textos positivos que ya no aceptan la hegemonía de los códigos procesales decimonónicos y que ya no se inspiran en la misma filosofía que éstos tuvieron.

La impetuosa sociedad actual cuestiona profundamente los cimientos sobre los cuales descansaron los juicios en el siglo XIX. Lo anterior se ha traducido en un claro cuestionamiento de los propios fundamentos de la tutela cautelar, alterándose la finalidad que tradicionalmente cumplió. En esta materia paulatinamente se ha avanzado de una concepción eminentemente conservativa o precautoria (piénsese en las figuras en torno a las cuales se realizó la construcción dogmática procesal de las medidas cautelares en Chile secuestro, retención de bienes, prohibición de celebrar actos y contratos, nombramiento de interventor judicial, entre las más significativas) hacia un plano anticipativo de la resolución del litigio.

\section{Finalidad de las medidas cautelares.}

En términos simples se puede afirmar que las medidas cautelares pueden cumplir dos fines: conservativos, por una parte, e innovativos, por la otra ${ }^{9}$. Los

8 Curia Filípica Mexicana, UNAM, México, 1978, edición facsimilar 1850, págs. 185 y 186.

9 En el derecho inglés se distingue precisamente entre las probibitory injunctions, por una parte, y las mandatory injunctions, por la otra, según que disuadan a una persona de efectuar un acto específico, o lo requieran para 
primeros nunca han presentado problemas en la doctrina nacional y comparada; los segundos, en cambio, han sido objeto de una profunda discrepancia.

\section{A. Finalidad conservativa.}

Estamos frente a medidas que ejecutan la finalidad tradicional de la tutela cautelar, a saber, aquéllas que sirven para «facilitar el resultado práctico de una futura ejecución forzada, impidiendo la dispersión de los bienes que pueden ser objeto de la misma» ${ }^{10}$. En el ordenamiento procesal civil chileno se puede considerar a cualquiera de las medidas precautorias previstas en el referido título $\mathrm{V}$ del libro II del CPC, como ejemplos que en definitiva buscan asegurar un conjunto de bienes con miras al cumplimiento posterior del fallo. Son medidas cuyo principal objetivo es conservar la situación de hecho y/o de derecho que se ve amagada por un preciso periculum que cada medida regula en concreto. Así, por ejemplo, si el conflicto surge debido al cuestionamiento de las facultades de quien aparece como propietario de una cosa y se ejerce en su contra una acción real (v. gr. la de dominio), será suficiente para evitar el peligro de que la cosa desaparezca o se deteriore con privar al aparente propietario de alguna de las facultades que legalmente ejerce sobre ese concreto bien. Si lo que se ejerce, en cambio, es una acción personal (por ejemplo, la indemnizatoria por la comisión de un hecho ilícito de los previstos en los artículos 1.314 y ss. del Código Civil) y lo que se busca por tanto es el pago de una determinada suma de dinero, será suficiente para evitar el riesgo de insolvencia del sujeto demandado con privarlo de la disposición jurídica de uno o más bienes integrantes de su patrimonio.

Sin duda son las diferentes medidas cautelares que integran esta categoría, con sus respectivos fines precautorios, las que siguen constituyendo la base de toda construcción dogmática que pretenda realizarse en torno a la tutela cautelar. El cuestionamiento que en las últimas décadas se viene realizando de los fines que tradicionalmente esta tutela ha cumplido no pasa en ningún momento por eliminar de su estudio estas medidas. Continúan siendo muy importantes y su utilidad práctica es innegable al interior de los diferentes ordenamientos jurídicos y de allí que el ante proyecto del Código procesal civil no prescinde de ellas.

\section{B. Finalidad anticipativa.}

Esta finalidad ha sido la que más problema ha generado en la doctrina comparada. Así en el derecho español, a propósito de la regulación realizada por la Ley de Enjuiciamiento Civil de 1881, se había observado que: «Como antes se adelantó, la que se adopte como medida cautelar debe ser semejante ("parecida" u

llevar a cabo una actuación concreta SHARPE, Injunctions and specific performance, Toronto, 1983, pág. 4; BEAN, Injunctions, 7a. ed., Londres, 1996, pág. 3; SHERIDAN, Injunctions in general, Londres, 1994, pág. 1; SPRY, The principles of Equitable remedies, Reino Unido, 5a. ed., 1990, pág. 322.

10 CALamandreI, Introducción al estudio sistemático de las providencias cautelares, trad. de Sentis Melendo, Buenos Aires, 1945, pág. 56. 
Marín - las medidas cautelares en el ordenamiento jurídico chileno...

"homogénea", si se quiere) a la medida ejecutiva que en su día deba acordarse para la efectividad de la sentencia. De esta semejanza dependen por igual su utilidad y su licitud. El legislador, cuando regula una medida cautelar o el Juez cuando la ordena apoyándose en una autorización genérica, deben intentar siempre obtener, para el caso concreto, este difícil equilibrio: adelantar, de un lado, el mayor número posible de actuaciones ejecutivas (para asegurar su eficacia), y poner extremo cuidado, de otro, en que tales medidas no produzcan los perjuicios irreparables que causaria la ejecución de la sentencia, pues se estaría, entonces, adelantando la ejecución sin que exista título ejecutivo (o lo que es igual, sin que el demandante haya acreditado su derecho a la tutela, y sin que el juez. esté facultado para penetrar en el patrimonio del deudor)》» ${ }^{11}$.

En este sentido, la jurisprudencia sistemáticamente ha rechazado medidas en las que se ha pretendido alejar de los fines estrictamente conservativos. De ahí que informando un recurso de queja — que la Corte Suprema hace suyo al desechar el referido recurso- se indica:

Que, por su naturaleza, la institución de las medidas precautorias tiene como único y limitado objetivo el de asegurar el resultado de la acción deducida. Que en la especia se ha pedido que se decrete desde luego, y sin previa notificación como medida precautoria, la inmediata reincorporación en los cargos que desempeñaban los demandantes en la [...]en juicios del trabajo sobre nulidad de despidos. Que, a juicio de esta Corte no puede estimarse que "existan razones graves" para ordenar desde luego el cumplimiento de las precautorias solicitadas, en atención a que no se observa, con los antecedentes reunidos, que las susodichas medidas tienden a asegurar el resultado de la acción, toda vez que no procede confundir el garantizar lo pedido en una demanda, con la obtención plena de lo que con la interposición de la misma se pretende, pues aceptar otra interpretación aún entendiendo en la forma más amplia las finalidades de las precautorias - podría significar autorizar de manera encubierta a un Tribunal a decretar una verdadera orden de no innovar a lo obrado por particulares en relación, precisamente con los hechos que motivan el litigio ${ }^{12}$.

Como se aprecia se niega que estas medidas puedan tener fines más amplios que los asegurativos, y se descarta de plano que dichos fines puedan ser anticipativos de la pretensión deducida, como sería la inmediata reincorporación

11 Fernández, Derecho procesal civil, t. III, 3a. ed., segunda reimpresión, Madrid, 1994, págs. 338 y 339 (el destacado es mío). En el mismo sentido GUTIÉRREZ DE CABIEDES, observa que «otro elemento básico de toda medida cautelar es la homogeneidad pero no la identidad entre la medida que se pide y el derecho sustantivo deducido en el proceso». Ahora bien si esta homogeneidad, agrega el referido autor, «fuera tan absoluta que la medida cautelar llegara a identificarse con el derecho sustantivo cuya cautela se pide, se concluiría en el extremo opuesto, es decir, en la ejecución adelantada del derecho. En este caso, la medida dejaría de ser cautelar y se convertiría en una auténtica medida ejecutiva, se obtendría una ejecución adelantada, o sin título suficiente para la misma. Las medidas cautelares, como tantas veces hemos dicho, tienden a ser posible una ejecución, pero no a adelantar ésta o a confundirse con ella». "Elementos esenciales para un sistema de medidas cautelares», en El Sistema de medidas cautelares, Pamplona, 1974, pág. 16.

${ }^{12}$ RDJ., t. LXIX, (1972), segunda parte, sec. 2, págs. 26 y 27. 
de los trabajadores en los cargos que desempeñaban los demandantes en la Compañía.. En este mismo sentido la Corte Suprema también ha resuelto que «es inaceptable la medida precautoria en cuanto tiende a que por ella se decida que las cosas no pueden calificarse de comunes y se establezca, desde luego, que el poseedor no podrá ser privado del goce exclusivo de los bienes. Pretender que mediante un decreto de precautorias se altere la naturaleza juridica de los bienes, significaría un prejuggamiento de la cuestión de fondo, concediendo en el hecho, desde luego, lo que no puede ser sino un resultado del fallo del juicio» ${ }^{13}$. Descartándose de plano que estas medidas puedan tener otros fines que los meramente precautorios.

Tal vez el carácter de homogeneidad que pronto la doctrina española predicó de estas medidas, haya influido para retrasar la llegada de medidas con fines anticipativos en el derecho español, situación que puede haberse repetido en Chile al adherir parte de nuestra doctrina a dicho carácter ${ }^{14}$. Pero en la doctrina italiana se superó pronto tal inconveniente. Así, CALAMANDREI en 1936 ya había advertido que ciertas medidas cautelares decidían interinamente una relación controvertida, de cuya indecisión podrían derivarse a una de las partes daños irreparables. En estas medidas, que el autor italiano denominaba del tercer grupo o del grupo «C», la providencia cautelar consiste «precisamente en una decisión anticipada y provisoria del mérito, destinada a durar hasta el momento en que a esta regulación provisoria de la relación controvertida se sobreponga la regulación de carácter estable que se puede conseguir a través del más lento proceso ordinario» ${ }^{15}$.

\footnotetext{
13 RDJ, LVIII (1961), segunda parte, sec, 1a., pág. 222, (el destacado es mío). También se ha resuelto: «Que, por lo tanto, la aludida medida precautoria no impide proceder a la designación de administrador pro-indiviso de todos los bienes comunes heredados por don [...]». «Que aunque lo dicho es suficiente para resolver la cuestión materia de la apelación, conviene agregar, a mayor abundamiento, que los bienes que forman la herencia de don [...], sobre los cuales se alega derecho exclusivo, no han perdido, por tal alegación, su calidad de comunes, como tampoco por estar sometido el litigio el derecho de dominio, quedan excluidos de las medidas conservativas que mientras se decide la litis deben tomarse en resguardo de los derechos de todos los interesados. Lo contrario conduciría a dejar entregada a la mera voluntad de quien alegara derecho exclusivo, por el solo becho de invocarlo, la condición actual de los bienes y la pérdida inmediata del derecbo de cautelar su conservación y giro, o sea, que desde luego, se producirian los efectos propios del acogimiento por sentencia definitiva firme de las acciones de nulidad y reivindicatoria, lo cual es notoriamente antijurídico». RDJ, LX (1963), segunda parte, sec. 2a. págs. 168 y 169, (el destacado es mío).

14 Véase TAVOLARI, «La orden de no innovar en el recurso de protección (una manifestación de la tutela cautelar en el Derecho chileno)», en Justicia III (1992), págs. 685 y ss.

15 Introducción..., op. cit., págs. 58 y 59. Inclusive en la misma obra, CALAMANDREI había tenido oportunidad de observar que «la calificación de "cautelares" (o asegurativas, que es sinónimo) es la más apropiada para indicar estas providencias, porque es común a todas la finalidad de constituir una cautela o aseguración preventiva contra un peligro que amenaza. Pero no todas las providencias cautelares son conservativas: pudiendo en ciertos casos la cautela que mediante ellas se constituye consistir no en la conservación, sino en la modificación del estado de hecho existente. En todos los casos en que uno se encuentra frente a un estado de hecho de tal manera que, si la providencia principal pudiera ejecutarse inmediatamente, su eficacia se traduciría en frutos prácticos, la providencia cautelar mira a conservar aquel estado de hecho, en espera y con el objeto de que sobre el mismo pueda la providencia principal ejercer sus efectos (por ejemplo, el secuestro conservativo que determina la indisponibilidad en cuanto a la futura ejecución forzada de los muebles hoy existentes en poder del deudor); pero otras veces, cuando se trata de que la futura providencia principal constituya nuevas relaciones jurídicas o bien ordene medidas innovativas del mundo exterior, la providencia cautelar, para eliminar el daño que podría derivar del retardo con el que la providencia principal podrá llegar a constituir tales efectos, debe tender ya no a conservar el estado de hecho existente, sino a operar en vía provisoria o anticipada, los efectos constitutivos e innovativos que, diferidos, podrían resultar ineficaces o
} 
Marín - las medidas cautelares en el ordenamiento jurídico chileno...

Pareciera, entonces, que una finalidad anticipativa no es ajena a la tutela cautelar. Numerosos textos positivos modernos y una interpretación más amplia que en el derecho comparado vienen realizando los tribunales sobre normas que contienen una cláusula de cautela general, permiten incluir dentro de este ámbito providencias de claros fines anticipativos. En Chile, como hemos avanzado, la discusión se ha sido resolviendo normativamente —al menos en algunos ámbitos de esta tutela—, según lo veremos seguidamente.

\section{La tutela cautelar en algunas leyes especiales chilenas: derecho de familia, derecho laboral y propiedad industrial.}

En esta parte deseo analizar la regulación que en materia de medidas cautelares han efectuado las siguientes leyes: ley 19,968, de 30 de agosto de 2004, que creó los Tribunales de Familia; ley 19,996, de 11 de marzo de 2005, que modificó la ley 19,039 de Propiedad Industrial; ley 20,066, de 7 de octubre de 2005, de Violencia Intrafamiliar (esta última sólo referida en notas al pie); ley 20,087, de 3 de enero de 2006, que sustituye el procedimiento laboral contenido en el título V del Código del Trabajo; y ley 20,152, de 9 de enero de 2007, que introdujo diversas modificaciones a la Ley 14,908, sobre abandono de familia y pago de pensiones alimenticias.

En términos generales si bien estas leyes muestran un importante avance en la forma cómo debemos entender la tutela cautelar en Chile, conjugando armónicamente medidas de carácter conservativo con otras de nítidos fines innovativos, es censurable que a estas alturas el legislador haya sido incapaz de ofrecer una reglamentación uniforme de ella, sin que ni siquiera se advierta la utilización de un lenguaje común (así se habla indistintamente de medidas precautorias, de medidas cautelares, de potestad cautelar, de función cautelar) en las mismas. Incluso en algunos ámbitos se percibe una especie de esquizofrenia jurídica — claramente, por ejemplo, en muchos de los recientes cambios realizados a la ley 14,908 - , con un importante número de amenazas y sanciones, que lo llevan a uno a pensar seriamente si el legislador nacional ha entendido bien cuál es el papel que le corresponde en un Estado de Derecho.

\section{Derecho de familia.}

En esta materia se han previsto medidas que confieren amplias facultades al juzgador para que, en cada oportunidad, determine el peligro que debe evitarse con la concesión de la correspondiente resolución, misma que también deberá determinar. Estamos por primera vez en la legislación nacional frente al

inaplicables (se puede pensar, por ejemplo, en el derribo de un árbol que ofrece peligro [...]; o en la providencia de urgencia con que el proceso de separación personal el presidente constituye provisoriamente, a cargo de los cónyuges, la obligación de pasar alimentos al otro». Introducción..., op. cit., pág. 48 y 49. (El destacado es mío). 
reconocimiento expreso de una potestad cautelar genérica del juzgador. En uso de esta facultad, el juez de familia podrá conceder no sólo medidas que tengan un carácter asegurativo patrimonial, sino medidas que cubran otro tipo de peligros; así, por ejemplo, la seguridad de la mujer y/o la de los hijos, evidentemente no está referida exclusivamente a un asunto monetario. Muchas veces el acceder a la separación provisional de cuerpos y/o el otorgar la custodia provisional de los hijos a uno de los cónyuges, puede ser decisivo para evitar perjuicios difícilmente reparables con una indemnización posterior.

\section{A. Ley 19,968, de 30 de agosto de 2004.}

A 1.- Procedimiento ordinario: La referida normativa, que creó los tribunales de familia, se enmarca dentro del abanico de reformas estructurales a las que ha sido sometido el sistema judicial chileno en los últimos años. La necesidad de contar con una justicia especializada en materia de familia, que diera una respuesta oportuna y adecuada a los requerimientos de esta peculiar área del derecho, fueron recogidos en el nuevo procedimiento familiar que reguló la ley 19,968. En él destacan los principios de desformalización, de mayor colaboración de las partes y de actuación de oficio del juzgador. Si bien son principios teóricamente plausibles, la experiencia de estos años ha mostrado que las motivaciones humanas en ocasiones van más lejos que las buenas intenciones del legislador.

En nuestro ámbito, no hay duda que la decisión legislativa fue dotar a los jueces de enormes facultades cautelares. El Ejecutivo fue categórico en el mensaje que acompañó el respectivo proyecto de ley: «Con el objeto de posibilitar la adopción de medidas urgentes cuando la situación lo amerite, se otorga al juez de familia una potestad cautelar amplia, que puede ejercer tanto de oficio como a petición de parte».

De allí que el artículo 22 -dentro de las reglas generales del procedimiento- haya señalado:

Sin perjuicio de lo dispuesto en leyes especiales, en cualquier etapa del procedimiento, o antes de su inicio, el juez, de oficio o a petición de parte, teniendo en cuenta la verosimilitud del derecho invocado y el peligro en la demora que implica la tramitación, podrá decretar las medidas cautelares conservativas o innovativas que estime procedentes. Estas últimas sólo podrán disponerse en situaciones urgentes y cuando lo exija el interés superior del niño, niña o adolescente, o cuando lo aconseje la inminencia del daño que se trata de evitar.

Las medidas cautelares podrán llevarse a efecto aun antes de notificarse a la persona contra quien se dicten, siempre que existan razones graves para ello y el tribunal así lo ordene expresamente. Transcurridos cinco días sin que la notificación se efectúe, quedarán sin valor las diligencias practicadas. El juez de familia podrá ampliar este plazo por motivos fundados. 
En todo lo demás, resultarán aplicables las normas contenidas en los Títulos IV y V del Libro II del Código de Procedimiento Civil.

Sin perjuicio de lo anterior, tratándose del procedimiento previsto en el Párrafo primero del Título IV de esta ley, sólo podrán adoptarse las medidas señaladas en el artículo 71».

Como se puede apreciar, la disposición transcrita tiene varios elementos que debemos analizar detenidamente. En primer término, su carácter residual: las medidas que aquí se permiten son sin perjuicio de otras que puedan preverse en leyes especiales. Esto es lo que sucede, por ejemplo, en materia de violencia intrafamiliar (ley 20,066), o tratándose del pago de pensión alimenticia (ley 14,908), que cuentan con medidas específicas en sus particulares leyes.

En segundo lugar, lo que constituye una tradición en este ámbito: las medidas se pueden adoptar en cualquier etapa del procedimiento, sea en primera o en segunda instancia e, incluso en grado de casación. También se permite que se soliciten y concedan antes del inicio del proceso mismo. En este último evento tendrán el carácter de medidas prejudiciales y se regirán por lo dispuesto en el título IV del libro II del CPC, artículos 273 al 289. A raíz de esta amplia remisión, habrá que ver cómo van a aplicar los jueces de familia la presunción de dolo que se contiene en el artículo 280 del CPC, cuando el futuro actor no cumpla con las cargas previstas en dicho numeral.

En tercer término, estas medidas pueden ser decretadas de oficio por el tribunal. Tratándose de esta facultad los jueces deben ser extremadamente prudentes. No es bueno, incluso en una materia tan delicada como las relaciones de familia, que el juez sin petición del actor conceda motu propio una medida cautelar. El riesgo de perder la imparcialidad es muy grande y esto sí que desnaturalizaría la función propia del juzgador. No se olvide que por más que sea un procedimiento distinto del civil tradicional (al menos de ello se hace una abundante argumentación en el mensaje del Ejecutivo) estamos frente a una forma heterónoma de solución de la controversia, en que el juez es por definición el sujeto imparcial del proceso. Su posición no puede ser más antagónica a la que cumplen las partes. Estas últimas son los sujetos interesados en el conflicto. El juez el sujeto desinteresado del mismo. En este ámbito es preferible un juez que oriente a las partes, particularmente a la más débil, y no uno que directamente se alinee con sus intereses.

En cuarto lugar, para conceder estas medidas el juez tiene que analizar los clásicos conceptos creados por la doctrina italiana: peligro en la demora y fumus boni iuris. En relación con este último criterio, prácticamente se ha seguido la doctrina de CALAMANDREI. En efecto, este autor exige cierta veracidad en la pretensión; así observa que "por lo que se refiere a la investigación sobre el 
derecho, la cognición cautelar se limita en todos los casos a un juicio de probabilidades y de verosimilitud ${ }^{16}{ }^{16}$. En relación el peligro en la demora, recordemos que doctrina italiana ${ }^{17}$ ha puesto de relieve que la configuración de este periculum in mora es diferente según la función que desempeñe la medida cautelar. En este sentido, se habla de peligro de infructuosidad y de peligro de tardanza o de retardo; en efecto, en algunas ocasiones lo importante es que la medida cautelar asegure urgentemente la existencia de bienes o de la cosa objeto de la demanda en vista de la futura ejecución. En otras, en cambio, la medida cautelar lo que busca es acelerar provisoriamente la satisfacción de la pretensión deducida, porque de esperarse el completo desarrollo del juicio se pueden producir en el demandante perjuicios irreparables. Esta última situación es muy común en el ámbito familiar.

En quinto lugar el juez podrá decretar las medidas cautelares conservativas o innovativas que estime procedentes. Quizá si esta sea una de las alteraciones más trascendentes en este ámbito. El expreso reconocimiento de que el juez puede adoptar medidas no sólo de carácter conservativo sino, también, aquellas de carácter innovativo. No sólo medidas de estricta precaución, sino las que alteren el statu quo imperante. La norma, adicionalmente, no acota el número ni el tipo de medidas que el juez puede adoptar. Se pueden conceder todas aquellas que de acuerdo con las circunstancias de cada caso sean procedentes. Lógicamente ellas deben estar en estricta armonía con el daño que se pretende evitar. Así, por ejemplo, la suspensión de la patria potestad, la autorización de salida de un menor del país, la prohibición de comercialización de un bien de la sociedad conyugal, una declaración de interdicción, etc., son todas medidas plausibles de conceder si son útiles para resguardar un inminente daño. Sin duda que esta circunstancia constituye un gran avance en nuestra legislación y como tal debe celebrarse, pero los jueces deben ser especialmente cautelosos al momento de conceder una medida innovativa, porque los riesgos de error son mayores y, porque, la ingerencia en la esfera de la contraparte es máxima.

De allí que, razonablemente, el legislador haya sancionado que tratándose de estas medidas «sólo podrán disponerse en situaciones urgentes y cuando lo exija el interés superior del niño, niña o adolescente, o cuando lo aconseje la inminencia del daño que se trata de evitar». Por lo tanto, no se trata de que los jueces frente a cualquier temor concedan una medida de carácter innovativo, sino que se requiere

\footnotetext{
16 Introducción..., ob. cit., pág. 77. La jurisprudencia chilena en algunas ocasiones ha acogido este criterio. Así ha fallado que «por lo expuesto y los demás antecedentes hechos valer por las partes, por ahora la existencia del derecho reclamado en el juicio no aparece con fuertes probabilidades de verosimilitud en virtud de los comprobantes invocados por el sujeto activo de la gestión cautelar». Gaceta Jurídica, N 123, (1990), pág. 37

17 Calamandrei, Introducción..., ob. cit., págs. 71 y sgtes. Proto PISANi señala a este respecto: «Per comprendere i molti contenuti che i provvedimenti cautelari possono assumere, occorre distinguere due diverse specie di pericula in mora che la tutela cautelare può essere chiamata a neutralizzare: a) il c.d. pericolo $\mathrm{da}$ infruttuosità del provvedimento a cognizione piena, b) il c.d. pericolo da tardività del provvedimento a cognizione piena». Ližioni di diritto processuales civile, 2a. ed., Nápoli, 1996, pág. 660. O como ha señalado TARZIA refiriéndose a esta distinción de Calamandrei de peligro de infructuosidad y peligro de tardanza, «si tratta, anche qui, di una distinzione che e divenuta patrimonio comune della nostra dottrina». «La tutela cautelare», en Il nuovo processo cautelare, a cura de Giuseppe Tarzia, Padova, 1993, pág. XXVI.
} 
de una situación de urgencia cualificada, o que el interés de los sujetos involucrados lo justifique, o que la inminencia del daño requiera un actuar rápido y de máxima ingerencia por parte del juzgador.

En sexto término, en relación con la tramitación de estas medidas, ya sabemos que pueden solicitarse en cualquier etapa del procedimiento. Ahora bien, lo normal es que se pidan antes de iniciar el proceso (prejudiciales) o, junto con la presentación de la demanda, sin perjuicio, claro está, de poderse pedir también en la audiencia preparatoria (artículo $61 \mathrm{~N}^{\circ}$ 3). En el primer evento - prejudicialesrige la reglamentación prevista en el título IV del libro II del CPC. En el segundo, esto es, cuando la medida se pide junto con la presentación de la demanda, el actor puede requerir que se acceda a la medida y se lleve a efecto sin que se notifique a la contraparte. Si el tribunal determina que existen razones graves para ello (por ejemplo, porque es inminente el daño para el solicitante o porque de notificarse la medida pueden frustrarse sus fines) accederá a dicha petición y así lo ordenará expresamente. En este caso, el actor tiene el plazo fatal de cinco días desde que la o las medidas fueron concedidas para notificar la correspondiente resolución a la contraparte. Si no se materializa la referida notificación en el plazo aludido, las diligencias practicadas en razón de las medidas concedidas quedarán — de planosin valor. El referido plazo de cinco días puede ser ampliado por el tribunal si existen motivos fundados para ello. Lógicamente esta ampliación deber ser requerida antes de que el plazo venza. Notificada que sea la medida, surge la oportunidad de la contraparte de oponerse a la medida ya concedida. A falta de norma expresa en esta materia, para saber cómo se tramita esta oposición, parece razonable aplicar el artículo relativo a los incidentes (artículo 26).

Ahora bien, si el tribunal estima que no hay razones o que estas no son graves para prescindir de la notificación, entonces la resolución que concede la medida (la ley habla de llevar a efecto la medida con o sin notificación) debe notificarse. Con la notificación surge el derecho de la contraparte de oponerse a la medida ya concedida, en los términos recién vistos.

La resolución que se pronuncia sobre la solicitud de una medida cautelar puede ser impugnada a través del recurso de apelación. Este recurso de entablarse por escrito y se concederá en el solo efecto devolutivo (artículo $67 \mathrm{~N}^{\circ} 3$ ).

En resumen, el inciso segundo del artículo 22 parece dar a entender que frente a la petición de una medida cautelar el tribunal debe concederla o rechazarla de plano, esto es, con la sola presentación del solicitante. Si la concede puede llevarse a efecto con o sin notificación de la contraparte, dependiendo si hay o no motivos graves para ello. Una vez notificada nace el derecho de oposición del sujeto pasivo de la medida. Si el tribunal, pese a la oposición, mantiene la medida, de todos modos debe resolver sobre la continuidad de la misma en la audiencia preparatoria (artículo $61 \mathrm{~N}^{\circ} 3$ ley 19,968). Estas resoluciones pueden ser apeladas. 
A 2.- Procedimiento especial relativo a la protección de los derechos de los niños, niñas o adolescentes: El inciso final del artículo 22 dispone que «Sin perjuicio de lo anterior, tratándose del procedimiento previsto en el Párrafo primero del Título IV de esta ley, sólo podrán adoptarse las medidas señaladas en el artículo 71». La disposición alude al procedimiento especial relativo a la protección de los derechos de los niños, niñas o adolescentes. Tratándose de este procedimiento sólo pueden decretarse las medidas cautelares previstas en el artículo 71 . Veamos, por tanto, que dispone dicha norma.

Artículo 71 (inciso primero): «En cualquier momento del procedimiento, y aun antes de su inicio, de oficio, a solicitud de la autoridad pública o de cualquier persona, cuando ello sea necesario para proteger los derechos del niño, niña o adolescente, el juez podrá adoptar las siguientes medidas cautelares [...]».

Este inciso amplía considerablemente los sujetos legitimados que pueden solicitar las medidas aquí previstas. El legislador ha consagrado una especia de «acción cautelar popular» ya que la medida no sólo puede ser requerida por la autoridad pública o el juez de oficio, sino por cualquier persona — natural o jurídica- que esté interesada en la protección de los derechos del niño, niña o adolescente. Esta circunstancia rompe con la tradicional estructura del proceso civil — sólo las partes pueden actuar en el mismo-, y plantea el complejo tema de precisar si es razonable establecer una legitimación tan extensa como la sancionada. La experiencia ha mostrado que cada vez que amplía la legitimación para actuar en favor de intereses «superiores», que van más allá de los estrictos derechos de los involucrados, las consecuencias ha sido más bien nefastas.

Ahora bien, ¿qué medidas pueden adoptarse al amparo de este artículo? El propio inciso primero señala al respecto:

a) Su entrega inmediata a los padres o a quienes tengan legalmente su cuidado;

b) Confiarlo al cuidado de una persona o familia en casos de urgencia. El juez preferirá, para que asuman provisoriamente el cuidado, a sus parientes consanguíneos o a otras personas con las que tenga relación de confianza;

c) El ingreso a un programa de familias de acogida o centro residencial, por el tiempo que sea estrictamente indispensable;

d) Disponer la concurrencia de niños, niñas o adolescentes, sus padres, o las personas que los tengan bajo su cuidado, a programas o acciones de apoyo, reparación u orientación, para enfrentar y superar las situaciones de crisis en que pudieren encontrarse, e impartir las instrucciones pertinentes;

e) Suspender el derecho de una o más personas determinadas a mantener relaciones directas o regulares con el niño, niña o adolescente, ya sea que éstas hayan sido establecidas por resolución judicial o no lo hayan sido;

f) Prohibir o limitar la presencia del ofensor en el hogar común;

g) Prohibir o limitar la concurrencia del ofensor al lugar de estudio o de trabajo del niño, niña o adolescente. En caso de que concurran al mismo establecimiento, el juez adoptará medidas específicas tendientes a resguardar los derechos de aquéllos; 
h) La internación en un establecimiento hospitalario, psiquiátrico o de tratamiento especializado, según corresponda, en la medida que se requiera de los servicios que éstos ofrecen y ello sea indispensable frente a una amenaza a su vida o salud, e i) La prohibición de salir del país para el niño, niña o adolescente sujeto de la petición de protección.

Como puede apreciarse, estamos frente a un vasto número de medidas de las que se puede echar mano, las cuales — en su gran mayoría - no tienen relación con cuestiones estrictamente patrimoniales e, indudablemente, permiten innovar y romper con el statu quo imperante. Así, por ejemplo, la entrega inmediata del menor a sus padres o a quien tenga su custodia legítima; o en caso de urgencia el confiar al menor a una familiar, son un clásico ejemplo de medidas esencialmente innovativas. En cambio, prohibir o limitar la presencia del ofensor en el hogar común, o en el lugar de estudio o trabajo del niño o adolescente, o suspender las relaciones directas de una persona con ellos, son medidas de carácter más conservativo.

En el inciso tercero del artículo 71 se dispone que: «La resolución que determine la imposición de una medida cautelar deberá fundarse en antecedentes que sean calificados como suficientes para ameritar su adopción, de los que se dejará expresa constancia en la misma». En este ámbito el legislador exige que se acompañen antecedentes suficientes para conceder la medida requerida. Ellos estarán dados precisamente por el ámbito de protección de la respectiva medida. Así, por ejemplo, si se pide cautelarmente la entrega inmediata del menor a sus padres, los antecedentes suficientes deben mostrar el riesgo que para el menor significa permanecer — durante el transcurso del proceso- alejados de ello. Y así respectivamente.

Tratándose de las medidas prejudiciales, el legislador ha dado algunas normas propias. Así, en el inciso quinto del artículo 71 se señala que: «Cuando la adopción de cualquier medida cautelar tenga lugar antes del inicio del procedimiento, el juez fijará desde luego la fecha en que deberá llevarse a cabo la audiencia preparatoria, para dentro de los cinco días siguientes contados desde la adopción de la medida». Por lo tanto, el legislador previendo los efectos radicales que este tipo de medidas suelen producir, ha ordenado que el juez fije, dentro de los cinco días siguientes de la concesión de la medida prejudicial, la fecha en que se desarrollará la audiencia preparatoria. En este caso, será precisamente en esta audiencia dónde el sujeto pasivo discutirá la procedencia y corrección de la medida otorgada.

Finalmente, el inciso sexto del artículo 71 dispone que: «En ningún caso la medida cautelar decretada de conformidad a este artículo podrá durar más de noventa días». Esta disposición constituye un acierto del legislador. Ya hemos dicho que las medidas cautelares pueden causar graves trastornos. De allí que acotar su duración a un plazo predeterminado pueda mitigar en parte estos problemas. Hubiera sido razonable, en todo caso, que la disposición hubiese 
previsto la posibilidad de renovar la medida o las medidas decretadas al cumplirse el plazo fijado por el tribunal. Comprendo que la duración legal de este proceso no es superior a los noventa días señalados, pero ya sabemos que la realidad suele deparar más de alguna sorpresa.

A 3.- Procedimiento relativo a los actos de violencia intrafamiliar que son de competencia del juez de familia: El artículo 81 de la ley 19,968 dispone que corresponderá el conocimiento de los conflictos a que dé origen la comisión de actos de violencia intrafamiliar, regulados en la ley 19,235 [entiéndase la ley 20,066], al juzgado de familia dentro de cuyo territorio jurisdiccional tenga residencia o domicilio el afectado» ${ }^{18}$.

En el tema que nos ocupa, el artículo 92 de la ley 19,968 ha previsto una serie de medidas cautelares de protección de la víctima: «El juez de familia deberá dar protección a la víctima y al grupo familiar. Cautelará, además, su subsistencia económica e integridad patrimonial. Para tal efecto, en el ejercicio de su potestad cautelar y sin perjuicio de otras medidas que estime pertinentes, podrá adoptar una o más de las siguientes $[\ldots .].\rangle^{19}$.

En este inciso, en primer término, se establece el deber del juez de dar protección a la víctima y al grupo familiar, y de cautelar su subsistencia económica e integridad patrimonial. Para cumplir con estas obligaciones, el legislador ha entregado al juez de familia, entre otras facultades, una potestad cautelar amplia. En ejercicio de dicha potestad el tribunal puede conceder provisionalmente cualquier medida que estime pertinente y que sirva para dar cabal cumplimiento a dicha obligación, por ejemplo, fijar de inmediato una pensión de alimentos a cargo del agresor; prohibir la enajenación de cualquier bien de propiedad de los cónyuges, etc.. Adicionalmente el juez puede conceder una o más de las siguientes medidas que la propia disposición enumera:

1. Prohibir al ofensor acercarse a la víctima y prohibir o restringir la presencia de aquél en el hogar común y en el domicilio, lugar de estudios o de trabajo de ésta. Si

\footnotetext{
${ }_{18}$ La ley 20,066, por su parte, establece en el artículo 6 que «los actos de violencia intrafamiliar que no constituyan delito serán de conocimiento de los juzgados de familia y se sujetarán al procedimiento establecido en la ley $\mathrm{N}^{\circ} 19,968$ ».

19 Esto, además, se ve complementado con las medidas cautelares reglamentadas en el artículo $7^{\circ}$ de la ley 20,066 de violencia intrafamiliar, que son de competencia del juez de familia. Artículo $7^{\circ}$ «Situación de riesgo. Cuando exista una situación de riesgo inminente para una o más personas de sufrir un maltrato constitutivo de violencia intrafamiliar, aun cuando éste no se haya llevado a cabo, el tribunal, con el solo mérito de la denuncia, deberá adoptar las medidas de protección o cautelares que correspondan. Se presumirá que existe una situación de riesgo inminente como la descrita en el inciso anterior cuando haya precedido intimidación de causar daño por parte del ofensor o cuando concurran además, respecto de éste, circunstancias o antecedentes tales como: drogadicción, alcoholismo, una o más denuncias por violencia intrafamiliar, condena previa por violencia intrafamiliar, procesos pendientes o condenas previas por crimen o simple delito contra las personas o por alguno de los delitos establecidos en los párrafos 5 y 6 del Título VII, del Libro Segundo del Código Penal o por infracción a la ley $\mathrm{N}^{\circ} 17.798$, o antecedentes psiquiátricos o psicológicos que denoten características de personalidad violenta. Además, el tribunal cautelará especialmente los casos en que la víctima esté embarazada, se trate de una persona con discapacidad o tenga una condición que la haga vulnerable».
} 
Marín - las medidas cautelares en el ordenamiento jurídico chileno...

ambos trabajan o estudian en el mismo lugar, se oficiará al empleador o director del establecimiento para que adopte las medidas de resguardo necesarias.

2. Asegurar la entrega material de los efectos personales de la víctima que optare por no regresar al hogar común.

3. Fijar alimentos provisorios.

4. Determinar un régimen provisorio de cuidado personal de los niños, niñas o adolescentes en conformidad al artículo 225 del Código Civil, y establecer la forma en que se mantendrá una relación directa y regular entre los progenitores y sus hijos.

5. Decretar la prohibición de celebrar actos o contratos.

6. Prohibir el porte y tenencia o incautar cualquier arma de fuego. De ello se informará, según corresponda, a la Dirección General de Movilización, a la Comandancia de Guarnición o al Director del Servicio respectivo para los fines legales y reglamentarios que correspondan.

7. Decretar la reserva de la identidad del tercero denunciante.

8. Establecer medidas de protección para adultos mayores o personas afectadas por alguna incapacidad o discapacidad.»

Una vez más, como podemos percatarnos, el legislador ha entregado un amplio abanico de posibilidades al juez de familia para que éste, dependiendo de las concretas circunstancias que rodean al proceso que le toca resolver, adopte un o más de estas medidas. En este abanico se entrecruzan medidas claramente conservativas (números cinco y seis, por ejemplo) con otras de nítidos efectos innovativos (tres y cuatro, por citar algunas). Evidentemente, el juez de familia puede ordenar una y otras, conjunta o separadamente.

En el inciso segundo del referido artículo 92 ha dispuesto que: «Las medidas cautelares podrán decretarse por un período que no exceda de los 180 días hábiles, renovables, por una sola vez, hasta por igual plazo y podrán, asimismo, ampliarse, limitarse, modificarse, sustituirse o dejarse sin efecto, de oficio o a petición de parte, en cualquier momento del juicio. El juez, para dar protección a niños, niñas o adolescentes, podrá, además, adoptar las medidas cautelares contempladas en el artículo 71, cumpliendo con los requisitos y condiciones previstas en la misma disposición».

En este inciso, junto con reiterar el carácter esencialmente temporales que estas medidas presentan, se reconoce otra características que la doctrina predica de estas medidas: su variabilidad. Así MONTERO AROCA señala que «las medidas cautelares son variables, es decir, pueden ser modificadas e incluso suprimidas según el principio rebus sic stantibus, cuando se modifica la situación de hecho con base en la que se adoptaron» ${ }^{20}$. De allí que si varían las circunstancias que se

\footnotetext{
20 Trabajos de derecho procesal, Barcelona, 1988, pág. 434. En el mismo sentido, CALDERÓN CUADRADO afirma que «la posible modificación o incluso revocación de las medidas cautelares acordadas por el órgano jurisdiccional se basa en el principio "rebus sic stantibus", en los llamados límites temporales de la cosa juzgada y no en su carácter provisional». Las medidas cautelares indeterminadas en el proceso civil, Madrid, 1992, pág.
} 
tuvieron en vista para conceder la medida, puede el tribunal ampliarla (se mostró insuficiente); limitarla (resultó excesiva), modificarla (resultó inadecuada), sustituirla (hay otra más eficaz) o dejarla sin efecto (se mostraron infundadas). Todo esto de oficio o a petición del afectado y en cualquier momento del proceso.

En esta ley además se entregan algunas directrices al juez en relación con la manera de ejecutar la o las medidas concedidas. Esto es algo más bien inédito en nuestra legislación. Normalmente las normas sobre medidas cautelares no prevén esta circunstancia. En esta ley el artículo 93 dispone que: «El juez, en la forma y por los medios más expeditos posibles, pondrá en conocimiento de la víctima las medidas cautelares decretadas, otorgándole la certificación correspondiente». Agrega en el inciso segundo que: «Asimismo, el juez podrá requerir el auxilio de la fuerza pública, disponer su intervención con facultades de allanamiento y descerrajamiento y ejercer, sin más trámite, los demás medios de acción conducentes para el cumplimiento de las medidas cautelares decretadas».

De este modo, todo el procedimiento cautelar está diseñado —al menos teóricamente- para dar una cabal y expedita protección a la víctima de la violencia intrafamiliar. Se han entregado facultades a los jueces para dar plena eficacia y ejecución a las medidas que otorguen. Incluso, en caso de incumplimiento de la o las medidas adoptadas, el legislador ha previsto la posibilidad de arrestar, como medida de apremio, al infractor hasta por quince días, sin perjuicio de oficiar al Ministerio Público para los efectos de lo previsto en el inc. $2^{\circ}$ del artículo 240 del CPC (artículo 94 ley 19,968) ${ }^{21}$. En verdad es difícil imaginar más facultades en este ámbito, sin que se arriesgue seriamente la imparcialidad del juzgador.

\section{Ley 14.908, sobre abandono de familia y pago de pensiones alimenticias, modificada por la ley 20152, de 9 de enero de 2007.}

La mencionada ley establece en su artículo 6 inciso $1^{\circ}$ que «las medidas precautorias en estos juicios podrán decretarse por el monto y en la forma que el tribunal determine de acuerdo a las circunstancias del caso». Nuevamente estamos frente a una norma que otorga amplias facultades al juzgador, quien deberá en cada oportunidad determinar el tipo de peligro y la correspondiente medida cautelar. En ellas, es clarísimo cómo el legislador permite al tribunal adoptar cualquier medida cautelar, y por el monto que él estime oportuno, teniendo sólo como limitación las circunstancias fácticas del caso. De esta forma, el inciso $2^{\circ}$ del artículo $6^{\circ}$ añade que «toda resolución que fije una pensión de alimentos deberá determinar el monto y lugar de pago de la misma».

Aplicando este precepto los tribunales han establecido que «de acuerdo con lo dispuesto en el artículo 6 de la ley 14.908 podrán decretarse por el monto y

34. Vid., igualmente, ORTELLS, El embargo preventivo, Barcelona, 1984, pág. 42.

21 Similar contenido se reitera en el artículo 10 de la ley 20,066 de violencia intrafamiliar. 
en la forma que el tribunal determine de acuerdo con las circunstancias del caso y en uso de esta facultad la Juez de Menores [...] concedió a la demandante [...] la medida de retención — aun cuando no lo dice expresamente— del diez por ciento de los fondos que obtenga el demandado al dejar de prestar servicios en [...], para el solo efecto de asegurar el pago de futuras pensiones alimenticias $[\ldots]\rangle^{22}$.

Ahora bien, dentro de las medidas cautelares que establece esta ley, sin lugar a dudas la más importante es la relativa a los alimentos provisorios. Recientemente la ley 20,152 efectuó importantes modificaciones en este ámbito. De este manera, el actual artículo $4^{\circ}$ de la ley 14,908 señala lo siguiente: «En los juicios en que se demanden alimentos el juez deberá pronunciarse sobre los alimentos provisorios, junto con admitir la demanda a tramitación, con el solo mérito de los documentos y antecedentes presentados».

La norma, por tanto, obliga al juez a tomar una decisión escuchando sólo al solicitante de la medida ${ }^{23}$. Aquí es dónde el actor deberá acreditar el fumus y el periculum para que se concedan los alimentos. Obsérvese que en los alimentos provisorios el periculum in mora no está dado por el peligro de infructuosidad, sino por el peligro de retardo, esto es, por el temor a que la justicia llegue demasiado tarde. En estos casos si bien es posible que se dicten medidas que resguarden el efectivo cumplimiento de la futura e hipotética sentencia condenatoria, por ejemplo, prohibiendo la celebración de actos y contratos sobre determinados bienes de conformidad con lo dispuesto en el artículo 6 de la ley 14.908, lo relevante a la hora de fijar los alimentos provisionales es que el legislador presume, por el carácter urgentísimo que ellos tienen, que el solicitante de los mismos no puede esperar el desarrollo íntegro del proceso para ver satisfecha su pretensión ${ }^{24}$.

La posibilidad de actuación del demandado ha sido diferida hasta el momento en que se le notifique la demanda. A partir de ese momento tiene el plazo de cinco días para oponerse al monto provisorio decretado (artículo 4 inciso $2^{\circ}$ ). Al respecto el inciso $3^{\circ}$ del artículo 4 señala: «Presentada la oposición, el juez resolverá de plano, salvo que del mérito de los antecedentes estime necesario citar a una audiencia, la que deberá efectuarse dentro de los diez días siguientes». Lógicamente esta situación favorece la postura del actor. La oposición del demandado se formula respecto de una medida ya concedida. Quien revisa su planteamiento es el propio juez que la concedió. Es cierto que su resolución es

\footnotetext{
22 Fallos del Mes, N 323 (1985), pág. 642. Igualmente se ha fallado que «en la demanda entablada por doña [...] para que se le obligara al pago de una pensión alimenticia, consta que para garantir la acción se decretó la prohibición de enajenar y gravar el bien raíz [....]». RDJ, t. XXVI, segunda parte, sec. 1a. pág. 227.

${ }^{23}$ Incluso si el juez no se pronuncia sobre los alimentos provisorios, comete una falta o abuso perseguible de conformidad con lo señalado en el artículo 536 del Código Orgánico de Tribunales (artículo 4 inciso final).

$24 \mathrm{Al}$ respecto los tribunales chilenos ha señalado que «la concesión de alimentos provisorios es un medio de conservarle la existencia al alimentario, buscando el legislador que, a través de ellos, se provea con urgencia a la satisfacción de las necesidades de aquél mientras se dilucida la acción que las difíciles circunstancias lo obligaron a entablar». RDJ., t. LXXVIII (1981), segunda parte, sec. 2a. pág. 34.
} 
apelable (inc. $6^{\circ}$ artículo 4), pero entre la concesión de la medida y su eventual alzamiento por el juez de segunda instancia puede transcurrir mucho tiempo.

Incluso el inc. $3^{\circ}$ del artículo 4 dispone que «Si en el plazo indicado en el inciso segundo no existe oposición, la resolución que fija los alimentos provisorios causará ejecutoria». Por lo tanto, si el demandado no presente su contradicción en el plazo establecido, los alimentos provisorios pueden ejecutarse desde luego. Por el contrario si se hubiere ofrecido una oposición, la medida cautelar sólo puede materializarse una vez que el tribunal resuelva la contradicción. Esta resolución normalmente será de plano, a menos que el tribunal estime necesario citar a una audiencia para dentro de los diez días siguientes.

Como vemos previo a discutir sobre el fondo de la cuestión y, por tanto, previo a que se determine si en definitiva el demandado es obligado al pago de alguna clase de alimentos, puede verse compelido a entregar una suma de dinero a título provisional por conceptos de alimentos; suma que se pagará durante el transcurso de todo el procedimiento y hasta que se dicte la sentencia definitiva en la causa, a menos, claro está, que durante el proceso obtenga el cese de la pensión.

En los términos descritos, estos alimentos constituyen una clara medida cautelar de fines innovativos, esto es, de aquellas medidas que se pronuncian interinamente sobre la pretensión deducida en el proceso ${ }^{25}$.

\section{Materia laboral: ley 20,087 que reemplazó el capítulo II (principios formativos del proceso y procedimiento en juicio del trabajo), del título I, del libro V, relativo a la jurisdicción laboral, del Código del Trabajo.}

Si bien la nueva justicia laboral debió entrar en vigor el 1 de enero de 2007, los enormes problemas que se han presentado en la implementación de la reforma en materia de familia, y el temor de repetir la experiencia ahora en este ámbito, llevaron al Ejecutivo — razonablemente, en todo caso- a diferir dicha vigencia hasta marzo del siguiente año. De este modo, lo que ahora se analice debe entenderse que se aplicará recién — si no vuelve a suspenderse- a partir de marzo de 2008.

La reforma en cuestión ha sido un tema sensible en el país. El Ejecutivo justificó los cambios en materia laboral de la siguiente manera:

En la actualidad existe consenso a nivel de los ciudadanos y de

los operadores del derecho laboral, de las falencias de nuestra

\footnotetext{
${ }^{25}$ La jurisprudencia ha señalado que «la dación de alimentos provisorios importa jurídicamente acceder desde luego y provisionalmente a lo pedido en la demanda presentada al juicio o, en otros términos significa el reconocimiento en igual forma del derecho que asiste al demandante para reclamar los alimentos definitivos, por lo cual es aplicable el artículo 331 del Código Civil, y, en consecuencia, los referidos alimentos se deben desde la presentación de la demanda en el juicio principal». RDJ, t. XXIX segunda parte, sec. 2a. pág. 101.
} 
justicia del trabajo. En efecto, la percepción de la comunidad jurídica laboral es que el acceso a la justicia laboral y previsional y su funcionamiento, plantean serios problemas de equidad y de efectiva vigencia del derecho, en razón de las insuficiencias que presenta, afectando principalmente a quienes recurren ante el órgano jurisdiccional, normalmente trabajadores que han perdido su empleo y que carecen de los medios necesarios para el sustento familiar.

El sistema vigente, caracterizado por la excesiva tardanza en la tramitación de los procesos laborales, producto tanto de la insuficiente cobertura de los tribunales como por la propia conformación del procedimiento, plantean serias dificultades en relación con el debido acceso a la justicia por parte de los trabajadores, produciendo con ello sentimientos de frustración y desencanto y la sensación de que aquellos derechos que les son reconocidos en la práctica se transforman en letra muerta.

Es un hecho que los demandantes de justicia laboral deben postergar sus expectativas de solución jurisdiccional, debido a lo extenso de los procesos y a las dificultades para ejercer patrimonialmente los derechos declarados en juicio.

Es por ello, que se hace patente e impostergable la necesidad de introducir profundas transformaciones en el sistema de la justicia laboral y previsional, con miras a implementar en Chile un modelo de relaciones laborales que dé cuenta de un mayor nivel de equidad y equilibrio, asegurando niveles adecuados de bienestar social y económico.

Como podemos ver, la reforma se enmarca dentro del mismo rumbo que previamente han transitado las reformas penal y familiar. Los conflictos en materia laboral requieren de un procedimiento especial que de plena efectividad a los derechos de la parte más débil —normalmente el trabajador- y que al mismo tiempo resuelva el conflicto dentro de uno parámetros de duración razonables. El ideal chiovendano sigue siendo el mismo: la «necesidad de servirse del proceso para obtener la razón no debe convertirse en un daño para el que tiene la razón».

Tratándose de las medidas cautelares se señaló en el aludido mensaje:

Se amplía la facultad del juez para decretar cualquier medida cautelar que estime necesaria para asegurar el resultado de la acción, así como para la protección de un derecho o la identificación de los obligados y de su patrimonio.

Se dispone, además, que la función cautelar del tribunal comprende la posibilidad de requerir información de organismos públicos, empresas u otras personas jurídicas o naturales, sobre cualquier antecedente que a criterio del juez contribuya al objetivo de su función, incluidos las deudas, créditos, bienes, valores y otros derechos de las partes, así como 
los de sus empresas o personas relacionadas o que tengan interés en ella.

De este modo, el artículo 444 en su inciso $1^{\circ}$ señaló: «En el ejercicio de su función cautelar, el juez decretará todas las medidas que estime necesarias para asegurar el resultado de la acción, así como para la protección de un derecho o la identificación de los obligados y la singularización de su patrimonio». Al igual que sucede en materia de familia, se reconoce explícitamente la existencia de una función cautelar. Debemos entender que el legislador ha querido referirse a una potestad cautelar genérica. En uso de esta facultad, el juez del trabajo puede adoptar cualquier medida que considere idónea para asegurar el resultado de la acción, la protección de un derecho, la identificación de los obligados y la individualización del patrimonio del obligado. De este modo el número, identificación y fines de la medida cautelar se ven ampliados considerablemente. El número será las que el juez considere necesarias, uno, dos o más. La identificación de las mismas simplemente se conforma con las que sean necesarias para asegurar el resultado de la acción, sean conservativas o innovativas. Y los fines son los que la propia norma señala.

En el inciso segundo del artículo 444 se añade: «Las medidas cautelares podrán llevarse a efecto antes de notificarse a la persona contra quien se dicten, siempre que existan razones graves para ello y el tribunal así lo ordene. Transcurridos cinco días sin que la notificación se efectúe, quedarán sin valor las diligencias practicadas». La norma es similar a lo analizado en el artículo 22 inciso

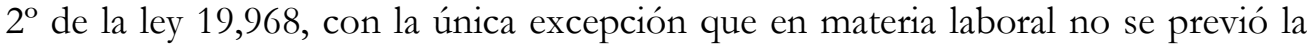
posibilidad de extender el plazo para realizar la notificación de la demanda. Las razones de este cambio para mí no son claras ni razonables.

El inciso $3^{\circ}$ del artículo 44, el más extenso, se expresa lo siguiente: «Las medidas precautorias se podrán disponer en cualquier estado de tramitación de la causa aun cuando no esté contestada la demanda o incluso antes de su presentación, como prejudiciales. En ambos casos se deberá siempre acreditar razonablemente el fundamento y la necesidad del derecho que se reclama. Si presentada la demanda al tribunal respectivo persistieran las circunstancias que motivaron su adopción, se mantendrán como precautorias. Si no se presentare la demanda en el término de diez días contados desde la fecha en que la medida se hizo efectiva, ésta caducará de pleno derecho y sin necesidad de resolución judicial, quedando el solicitante por este solo hecho responsable de los perjuicios que se hubiere causado. Con todo, por motivos fundados y cuando se acredite por el demandado el inminente término de la empresa o su manifiesta insolvencia, el juez podrá prorrogar las medidas prejudiciales precautorias por el plazo prudencial que estime necesario para asegurar el resultado de la litis».

En primer término reitera lo visto en la ley 19,968 y lo que dijimos es una tradición en este ámbito: las medidas cautelares pueden requerirse antes o después de la presentación de la demanda, y en este último evento en cualquier etapa del 
proceso. No hay ninguna restricción al respecto. En cuanto a su tramitación, si bien no hay una referencia expresa en este artículo, dado lo similar que resulta este procedimiento con el de familia, se puede aplicar lo que hemos dicho a propósito de la ley 19.968 (procedimiento ordinario). Así en el procedimiento laboral también existe una audiencia preparatoria en la que el juez decretará las medidas cautelares que procedan, o se pronunciará sobre su mantención si ya hubieren sido decretadas con anterioridad (artículo $453 \mathrm{~N}^{\circ}$ 8). Del mismo modo, la resolución que se pronuncia sobre una medida cautelar puede ser impugnada a través del recuro de apelación. Apelación que se concederá en el solo efecto devolutivo (artículo 476). Si se estima que no resulta aplicable lo que hemos visto a propósito del procedimiento de familia, no queda más que aplicar la tramitación de las medidas precautorias prevista en el CPC (artículo 432 Código del Trabajo).

En segundo lugar, la norma señala lo que el actor debe atestiguar para que el juez le otorgue la medida — sea como prejudicial o como simple cautelar-: acreditar razonablemente el fundamento y la necesidad del derecho que se reclama. Curiosamente en esta parte el legislador se apartó de la reglamentación que vimos en la ley 19,968, donde inequívocamente se aludía a los clásicos fumus boni iuris y periculum in mora. Lo anterior obligará al interprete a un esfuerzo adicional para establecer si con estas palabras se está aludiendo a los mismos conceptos latinos, o si hay una diferencia con ellos. Pareciera que la idea de fundamento razonable puede ser reconducida a la idea de verosimilitud (por oposición a certeza) empleada en materia de familia. Y la idea de necesidad podemos entenderla que engloba la idea de peligro de no satisfacción del derecho en sede provisional.

Tratándose de las medidas prejudiciales la norma entrega algunas indicaciones que, en parte, se diferencian de la reglamentación de estas medidas existente en el título IV del libro II del CPC. En materia laboral el juez debe analizar, una vez que se hubiere presentado la demanda (¿debe pedir el mantenimiento de las medidas el actor?), si se mantienen las circunstancias que tuvo en vista para conceder la medida prejudicial. En caso afirmativo las ratificará; en caso contrario debe ordenar su alzamiento. Ahora bien, si el actor no presenta la demanda en el plazo de diez días siguientes de la fecha en que se hizo efectiva la medida, esta caducará ipso facto, sin necesidad de resolución judicial alguna, y el actor será responsable de los perjuicios que le medida hubiere ocasionado al demandado. La norma es similar a lo establecido en el artículo 280 del CPC, pero elimina la presunción de dolo allí prevista ${ }^{26}$.

El artículo 444 inciso $3^{\circ}$ contiene una excepción que para mí no es clara. Señala dicha norma: «[...] Con todo, por motivos fundados y cuando se acredite por el demandado el inminente término de la empresa o su manifiesta insolvencia, el juez podrá prorrogar las medidas prejudiciales precautorias por el plazo prudencial que estime necesario para asegurar el resultado de la litis». ¿Cuál es

${ }^{26}$ Veáse, mi libro Las medidas..., op.cit., págs. 298-305. 
alcance de esta excepción? Parece decir que si el demandado acredita el inminente término de la empresa o su manifiesta insolvencia, el juez puede prorrogar las medidas prejudiciales. Pero ¿por qué razón el demandado tendría interés en acreditar esta circunstancias?, más aun que esto serviría para prorrogar las medidas prejudiciales dictadas en su contra. Creo que es más razonable, en este caso, que sea el demandante (no el demandado) quien acredite esta circunstancia, entonces, sí tiene sentido que el juez, pese a que la medida ya caducó, la renueve por el plazo prudencial que estime necesario para asegurar el resultado de la litis.

Finalmente, el inciso final del artículo 444 dispone que «Habiendo sido notificada la demanda, la función cautelar del tribunal comprenderá la de requerir información de organismos públicos, empresas u otras personas jurídicas o naturales, sobre cualquier antecedente que a criterio del juez contribuya al objetivo perseguido». Vemos aquí una especie de norma de cierre del sistema. En uso de esta facultad cautelar, una vez notificada la demanda, el juez tiene amplia competencia para requerir la información que estime pertinente, de organismos públicos o privados, y que en su concepto sea útil para resolver adecuadamente el conflicto. Por ejemplo, si el tema en discusión es el monto al que debe ascender la gratificación anual del trabajador, pedir información a la Superintendencia de Sociedades Anónimas sobre el estado de resultado de la empresa puede ser de gran utilidad.

\section{Propiedad Industrial.}

En esta materia ha observado la doctrina extranjera: «Hay ciertas obligaciones que sólo se pueden asegurar anticipando la ejecución de la sentencia y de hecho la LP [ley de patentes] nos permite expresamente adoptar la medida cautelar de cesación de actos para garantizar la acción de cesación de actos» ${ }^{27}$. En parte es lo que ha ocurrido en el ordenamiento jurídico nacional. En efecto, la ley 19.996, de 11 de marzo de 2005, introdujo importantes modificaciones a la ley 19.039, de propiedad industrial. En lo que ahora nos importa, se incorporó un título X, relativo a la observancia de los derechos de propiedad industrial, con tres párrafos, que tratan respectivamente, de las acciones civiles (párrafo $1^{\circ}$ ); de las medidas precautorias (párrafo $2^{\circ}$ ); y de las medidas prejudiciales (párrafo $3^{\circ}$ ).

La idea que está detrás de estas modificaciones es muy clara: los derechos de propiedad industrial no se encontraban debidamente amparados en la legislación chilena, prestándose esta situación para innumerables abusos. Como se sabe, Chile es uno de los países que goza de una horrible reputación en la lucha contra la piratería. En esta materia, donde la regulación del derecho internacional tiene enorme ingerencia, se requería alguna adecuación de la ley chilena.

${ }^{27}$ PÉREZ Daudí, Las medidas cautelares en el proceso de propiedad industrial, Barcelona, 1996, pág. 96. 
De este modo, el artículo 106 dispuso que el titular cuyo derecho de propiedad industrial sea lesionado podrá demandar civilmente:

a) La cesación de los actos que violen el derecho protegido.

b) La indemnización de los daños y perjuicios.

c) La adopción de las medidas necesarias para evitar que prosiga la infracción.

d) La publicación de la sentencia a costa del condenado, mediante anuncios en un diario a elección del demandante. Esta medida será aplicable cuando la sentencia así lo señale expresamente.

Para hacer verdaderamente efectivos los derechos reconocidos en el artículo 106 —en ocasiones la única forma de hacerlo—, se adicionó un párrafo $2^{\circ}$, al título $\mathrm{X}$ de esta ley, intitulado, De las medidas precautorias, con un artículo que contiene importantes medidas cautelares. Si bien en este punto, a diferencia de lo que hasta ahora hemos visto, no se entregó una potestad cautelar genérica, sí se previeron medidas de carácter innovativo que, junto con otras más tradicionales, y una cláusula abierta para conceder «otras medidas precautorias», dan buena movilidad a los jueces para proteger los derechos de propiedad industrial. Es lamentable, en todo caso, que finalmente — no era así en el proyecto del Ejecutivo- sólo se hubiere dedicado un artículo a este rubro. Tal vez una regulación más detallada hubiera despejado muchas dudas que ahora quedan.

Señaló el artículo 112 al respecto: «Las medidas precautorias procederán en todos los asuntos que digan relación con infracciones a los derechos de propiedad industrial. Sin perjuicio de otras medidas precautorias, el Tribunal podrá decretar las siguientes:

a) La cesación inmediata de los actos que constituyan la presunta infracción;

b) El secuestro de los productos objeto de la presunta infracción y de los materiales y medios que sirvieran principalmente para cometerla. Tratándose de signos distintivos, podrá además decretarse el secuestro de los envases, embalaje, etiquetas, material impreso o de publicidad que posean el signo motivo de la presunta infracción;

c) El nombramiento de uno o más interventores;

d) La prohibición de publicitar o promover, de cualquier manera, los productos motivo de la presunta infracción, y

e) La retención, en poder de un establecimiento de crédito o de un tercero, de los bienes, dineros o valores que provengan de la venta o comercialización de dichos productos, en cualquier forma.

Como se puede apreciar, la disposición le entrega al juez la facultad para conceder tanto medidas precautorias conservativas como innovativas. Son estas últimas las que en el derecho comparado se han mostrado de mayor utilidad en esta materia. Así, por ejemplo, obtener el cese inmediato de los actos que constituyan la infracción resulta una medida clave para hacer efectivos los derechos aquí amparados. Así, la suspensión inmediata de la venta de productos que utilizan indebidamente una marca puede ser de mayor utilidad que una 
eventual indemnización posterior. Lo mismo, por ejemplo, si cautelarmente se prohíbe publicitar o promocionar los productos indebidamente utilizados.

Estas medidas, además, pueden solicitarse como prejudiciales, según lo afirma el artículo 113 de esta ley: «Podrán solicitarse como medidas prejudiciales, las precautorias de que trata el Párrafo $2^{\circ}$ del Título $\mathrm{X}$ de esta ley y las medidas contempladas en los Títulos IV y $\mathrm{V}$ del Libro Segundo del Código de Procedimiento Civil».

Incluso - estas son partes de las dudas- debemos entender que en relación con los requisitos de concesión de estas medidas, así como la forma cómo se tramitan se aplican supletoriamente los títulos IV y $\mathrm{V}$ del libro segundo del CPC. Lo mismo debemos predicar de las medidas precautorias referidas en el artículo 112 de esta ley.

\section{Conclusión.}

A lo largo de este trabajo hemos podido ver sucintamente los importantes cambios que en la legislación nacional se vienen produciendo en materia de medidas cautelares. Si bien muchos de los cambios resultan plausibles, tendremos que analizar cómo en definitiva los jueces chilenos comienzan a utilizar las amplias facultades cautelares de la que ahora disfrutan. Las medidas cautelares son herramientas sumamente sutiles, que requieren de una enorme precisión en su utilización. Son extremadamente útiles y extremadamente dañinas. Sólo si el juez entiende a cabalidad cuál es la función que le corresponde en un Estado de Derecho, y actúa prudentemente al manejar el arsenal del que ahora dispone, podremos decir que hemos avanzado decididamente en este ámbito. 